\title{
AN ACTIVE CONSUMER THEORY PERSPECTIVE ON BLOGS
}

\author{
Seung C. Lee, University of Minnesota at Duluth, slee@d.umn.edu
}

\begin{abstract}
Our primary goal of this paper is to contribute to a theoretical understanding of why we blog by suggesting a general view on the explosive popularity of blogging through the analysis of the behavior of bloggers and the consumption of blogs from a perspective of the active consumer theory. A further goal is to provide a review of competing theories and previous work that could explain the aspects of blogging and bloggers from different angles.
\end{abstract}

Keywords: Active Consumer, Blogs, Bloggers, Utility

\section{INTRODUCTION}

A blog is a frequently updated website that consists of the entries of personal opinions, observations, excerpts from other sources and so on, which is typically run by a single person and encourages the readers to comment on the entries and contribute to the site. The advent of blogs dates back to Tim Berners-Lee, who created the first website while he was at CERN, and Dave Winer, who established a scripting news site in $1996[22,28]$. Since then, numerous blogs hosting a wide variety of themes have emerged. However, it was not until the 2004 presidential election of the US did people realize the potential of blogs. The unprecedented success in the political campaign on the blog also hinted that blogs would change and influence almost everything from politics to journalism $[23,26]$.

Then what makes blogging so popular and influential over conventional discussion forums, websites, and the other Web-based information sharing mechanisms? Why does the number of bloggers ever increase and why do people surf everyday to blogs? Are there any new features of blogs that the conventional mechanisms cannot match? Or simply, is blogging a fad? We could find the answer in the social network and social psychology theories because blogs link themselves into a vast network and because bloggers are considered to be motivated by the relationship between their minds and social behaviors $[8,19,26,27]$. A recent study has identified five motivations for blogging, such as catharsis [6]. Other studies suggested that blogs are so popular because blogging is the latest genre of
Internet communication and bloggers are early adopters of the genre driven by the personal and professional stickiness [9, 10]. All these findings have their own merits, but they seem to miss the fundamental notion: a blogger is both a consumer and a producer-in short, an active consumer-and blogging is the discovery process of improvement, change, and novelty potential of blogs, which is enjoyable in itself.

In this paper we characterize a blog as a good, blogging as a novelty-seeking behavior, and a blogger as an active consumer who also actively produces his or her own wellbeing out of the blogging on a blog. In other words, regardless of blog types (see [4, 14]) and their content, we see blogging as a matter of consumer choice. A blogger as a consumer, in the usual way, chooses her own efficiency frontier [29] that describes the maximum outcome obtainable with given resources. Furthermore, a blogger as a producer tries to maximize his utility through the innovative and creative discovery process of novelty, autonomy, creativity, and reachability, which are also determinants of the blogger's utility function. Our primary goal of such characterization is to contribute to a theoretical understanding of why we blog by suggesting a general view on the explosive popularity of blogging through the analysis of the behavior of bloggers and the consumption of blogs from a perspective of the active consumer theory.

\section{BACKGROUND}

\section{Blogs as a New Communication Genre}

Recent years have seen a growing interest in the communications genres on the Web including blogs (e.g., [10]). Blogs facilitate social interaction online by removing the technological barriers associated with creating and maintaining websites. They have also added new dimensions-pleasantness and efficiency-to the social interaction, which have often been suppressed or eliminated from conventional genres of Internet communication [4]. Blogs are inherently versatile, interactive, cohesive, and accessible. There is also the possibility to incorporate other forms of communication genres into a blog. For instance, email has been found to be a reliable means to direct people to blogs [19]. Blogs 
compete for attention and audience in general. This forms the realm of control and influence of blogs. The broader and wider the audience base, usually the better. But maintaining a blog to sustain a loyal audience is a challenge because the preferences for bloggers are not clearly defined and understood.

\section{SOCIAL NETWORK AND PSYCHOLOGY VIEW OF BLOGS}

The dynamic nature of blogs attracts and involves bloggers who are actively transforming their innate characteristics to a new level of information communication through networking. This matrix taken apart involves the concepts of social network and psychology theories. Network theory presents a collection of entities as a single unit by creating relationships in the form of connections to form a network [19]. In a network, every entity is connected in one form or another with another entity. Entities within networks interact with each other. These interactions dictate the distribution of power or value in the network [8]. According to this definition, all blogs can be considered as entities within a network of blogs. A link forms the relationship between one blogger and another. Understanding the relationships between blogs and how these relationships are created, thus can be crucial to understand blogging and bloggers alike.

The basic notion of psychology theory that pertains to blogging is the integration principle: bridging the gap between online and offline experiences [26]. The study shows a natural tendency to maintain a balance between one's offline and online living. With the presumption that online experience is relatively new, for most people would the shift to maintaining this balance continue toward an increase in online presence. With blogs emerging as a convenient tool for this transition, there would be an increasing trend toward online experience with the purpose of achieving a balance between the online and offline experience.

\section{ACTIVE CONSUMER MODEL}

An active consumer is defined as a consumer who consumes goods in creative ways by finding new ways of use, modifying established goods, or creating new functions of the given goods [11]. Thus, an active consumer is also an active producer who constantly finds herself transforming goods into something that is pleasant to her. But what is pleasant to her is not inscribed in the goods already available; it has to be discovered. This approach takes account of the consumer's pursuit of novelty and taste for novelty through which consumers gain efficiency by improving goods' functional properties and find pleasantness from the novelty-seeking process. Novelty can be defined as a disparity between present and past experience [6]. The degree of this disparity can be found in a very wide continuum. The novelty discovery process is the creation ex nihilo of options that did not exist before by creating and adding value as well as differential advantage for him or her [13]. The discovery process generates novelty, which is one of the fundamental drives for consumer behavior. Consumers seem to have pleasantness in trying newly discovered goods or new solutions, exploring new characteristics or combinatory possibilities of goods. The active consumer theory is therefore premised on the assumptions that (1) the consumer is also an active entrepreneur of his or her own utility or wellbeing; (2) the production of individual wellbeing is an innovative, creative, and novelty-seeking process; and finally (3) novelty and surprise contribute to the consumer's utility function in a positive way because they are pleasant within limits. Surprise is something opposite to our existing set of expectations. Novelty too can be surprising when it is not expected, and vice versa, but there is a subtle difference between novelty and surprise. Something surprising may not be new, and in the same way, something new can be expected [6].

\section{ON BLOGGING AND BLOGGERS}

Then, what makes blogs and blogging so popular and influential over the other Internet communication genres? In this section we try to find the answer to the question in terms of the consumer's taste for novelty and choice of novelty, which are the abstractive underpinnings of the active consumer theory. Logically, we can think of bloggers as active consumers in that they read (or consume) entries and contribute to (or create) blogs as well by posting and commenting on their entries, while blogs are intangible goods that are part of available set of the goods that fall into the blogger experience.

\section{Preference for Novelty}

Blood [4, 22] noted that one finest site listed only 23 blogs in existence at the beginning of 1999. But it was the release of Blogger (http://www.blogger.com) in 1999 that made blogging into a hugely popular phenomenon. Today, blogs have gained such a widespread success, invading other Internet communication genres [23]. What has happened? Of course, for certain things to become popular, ease of creation is an important factor because it can attract novices to such things. But, as we can find similar 
phenomena from the historic events such as the wide popularity of Indian calicos, Wedgwood pottery, and tulips $[18,20]$, the blog's success is related to its intrinsic innovative qualities. They are a medium to document bloggers' lives; they are a form of democratic self-expression making bloggers' voices heard; it is an outlet for thoughts and feelings and the process of releasing strong emotions through writing and commentary; they are a muse that gives bloggers ideas and helps them to write about what they have been reading in the news and other publications; they are a community forum for bloggers' own interests such as design and gardening $[4,6,17,26]$. Blogs also provide better personal care, more freedom of expression, more blogger autonomy and independency, more extensive chain of network possibilities, and more flexibility in discovering new ways of their use due to their infinite diversity of subjects and themes. Finally, and importantly, blogs are a novelty, which combines such versatility and "self-rejuvenation," which is hard to find from the other applications, with the already existing pervasive and ubiquitous computing, whether it is wireless or wired. The result of all this is that blogs have become an Internet communication genre that carries an appeal and embodies a good degree of ingenuity that had seemed reserved not only for skilled Web users, but also for certain advanced communication tools.

\section{Choice of Novelty}

Lancaster $[15,16]$ sees the consumer as a productive agent who not only actively transforms inputs (goods) into outputs of bundles of distinctive, objective properties that distinguishes one good from another, but also produces and gains efficiency improvements. Given the characteristics associated with the new good, the efficiency frontier will expand, favoring those combinations that include the new good. Although his model solves the problem of choice of new goods, his definition of a new good is too limited because most new goods are new just because they provide novelty and/or surprise.

Meanwhile, Earl [7] incorporates uncertainty and unpredictability into consumer decisions based on the psychology theory of personal constructs [12]. According to the theory, the general public engages in translating environmental things and events into personal images and constructs to gain a degree of predictability and control. Thus, in a turbulent world consumers may avoid or look for novelty. Indeed, Krishnamurthy [14] examined patterns of posting to a news blog in the week immediately following the events of 9/11/2001 and found that the daily number of postings increased. Earl's analysis, however, does not incorporate the producer trait of the consumer into his or her decisions.

Yet another analysis of consumer behavior within the framework of active consumer theory stresses the pursuit of novelty as one of the fundamental drives of consumer behavior [21]. According to the study, which draws heavily on the work of Berlyne [6], novelty is a major source of human satisfaction, especially in the lack of stimuli. But why is novelty so enjoyable? Why do consumers keep looking for pleasantness even when all their needs are satisfied? That is because novelty together with variety, complexity, and surprise are the different sources of the stimulus $[6,21]$ or the arousal potential of a specific condition or experience. They contribute to the changes in the level of arousal, and the changes are associated with the sensations of pleasure. But it is not unbounded. As novelty and surprisingness increases, the level of pleasure increases up to a certain point and then decreases.

What conclusions can we draw from the above discussions? Unlike the selection of consumption set in traditional consumer choice theory, the process of selection in the context of the discussions depends on the goods' novelty potential and combinatory possibilities. There are two elements involved in this process. One is recognizability or, in other words, "skilled consumption" [21, p. 225]. The other element represents the potential for improvement, change, and novelty that a specific consumption choice set determines. Novelty appears to play a dual role in consumption. As pointed out by Lancaster $[15,16]$, it is linked to an efficiency gain for the consumer. In addition, the discovery process of the improvement, change, and novelty potential, which generates novelty, is pleasant in itself. To summarize efficiency and pleasure gains together with recognizability provides a framework for understanding how goods are chosen within the context of active consumer theory.

As stated before, we can think of bloggers as active consumers of blogs who are engaged in blogging as a consumption activity and produce their own wellbeing actively via blogging as well. Blogs are a new good in the set of the communication goods available for bloggers to choose from. Blogs are recognizable because they are more or less related to the previous communication genres and have a good degree of novelty potential and combinatory possibilities in that they can take numerous shapes and deal with virtually an infinite number of subjects. Thus, to derive an answer to the question of what makes blogs so popular, let $\mathrm{G}$ of Figure 1 be the set 
of the communication genres that fall into the blogger experience, and $g \in G$ be the chosen subset. Assume further, that the straight line $\mathrm{AB}$ of Figure 2 denotes the efficiency frontier (i.e., budget or resource constraint) of the chosen subset $\mathrm{g}$. As in traditional consumer choice theory, this represents the maximum outcome obtainable with given resources in terms of time, effort, and/or budget of a blogger when all his or her available opportunities have been exploited. But suppose now that the subset $g$ contains the possibility of innovation or change because of blogs as a new good included in the subset and because of its new characteristic, which alters the existing combinatory possibilities, and allows the blogger to discover better ones within the given resources (e.g., blogs' higher influence as compared with an already experienced communication genre such as discussion forum). It may also allow the blogger to be the producer of his or her wellbeing through a more efficient combination of existing communication genres or characteristics (e.g., embodying multimedia content with already existing communication genres such as email). As a result of such novelty-seeking behavior the efficiency frontier expands to the point $C$ in Figure 2 (see 25).

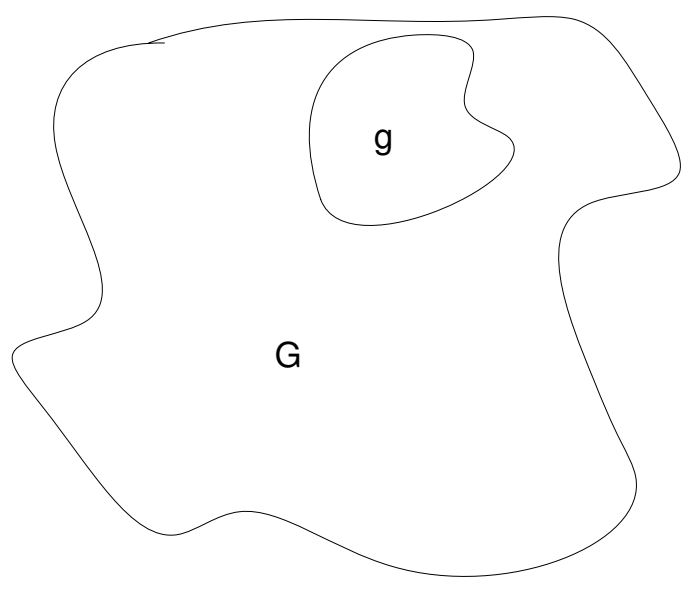

Figure 1. A Space of Goods and the Choice Set

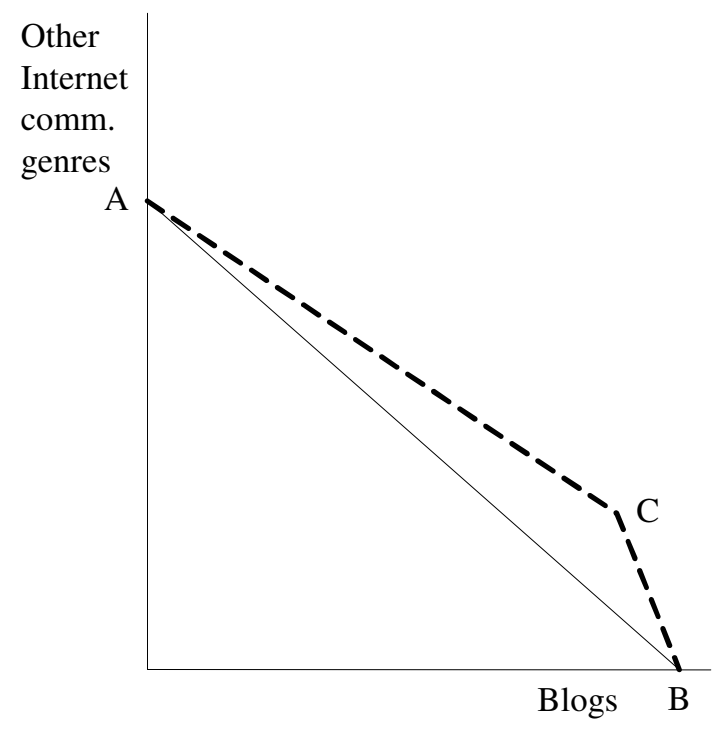

Figure 2. Local Efficiency Gains

In addition to the efficiency gains, novelty and its discovery give pleasantness and therefore can be an independent variable in the blogger's utility function. Consider the traditional utility function, utility $=\mathrm{U}(\mathrm{x})$, with $U^{\prime}>0$ and $U^{\prime \prime}<0$, where $x$ represents the choice set, as shown in Figure 3. Since discovery is pleasant, corresponding to the choice set $\mathrm{g}$, utility increases, as depicted by the dotted bump in Figure 3 . When we consider the Figure 2 and 3 together, both the efficiency and the utility gains due to novelty can be measured, as shown in Figure 4. This means that bloggers as active consumers should produce both. In traditional consumer choice theory, with or without the efficiency and the utility gains from novelty and novelty-seeking behavior, the blogger would choose the (o1, b1) set by matching the indifference curve, $\mathrm{I}_{t}$, to the efficiency frontier, $\mathrm{AB}$. In the active consumer theory, with the efficiency and the utility gains, the blogger would choose the (o2, b2) set by using the expanded efficiency frontier, $\mathrm{ACB}$, and the indifference curve, $I_{n}$. This analysis provides an answer to the question of what makes blogs so popular. 


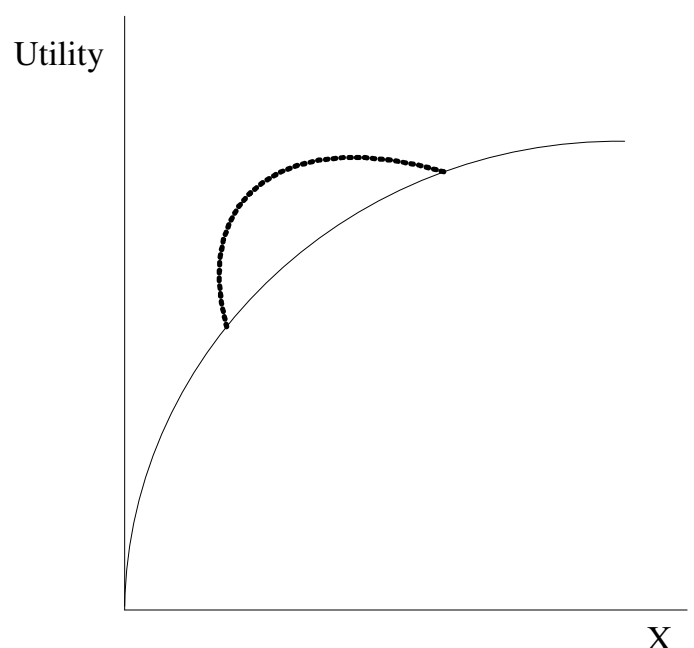

Figure 3. Local Utility Gains

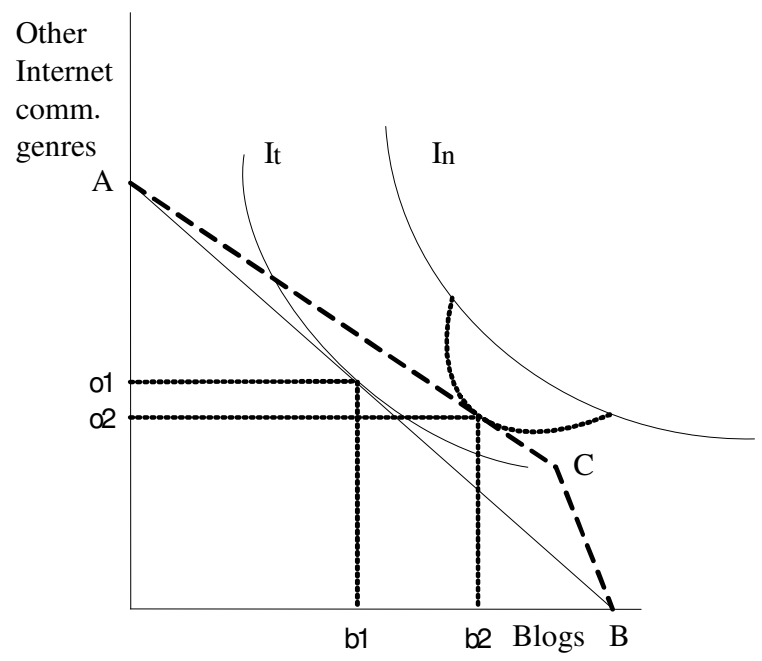

Figure 4. Local Efficiency and Utility Gains

\section{CONCLUSIONS}

Blogs are located at an upper middle point between standard websites and asynchronous communications along each of those dimensions [10]. However, blogs are truly distinguishable from the others because blogs provide better personal care, more freedom of expression, more blogger autonomy and independency, more extensive chain of network possibilities, and more flexibility in discovering new ways of their use due to their infinite diversity of subjects and themes. With all of these characteristics, blogs are novel goods, bloggers are active consumers, and blogging is a novelty-seeking behavior, which enables an expansion of efficiency frontier and an addition of utility of the bloggers. Both efficiency and utility gains appear to represent strong drives for the blogger to do blogging, which is viewed as a novelty-seeking behavior of them as active consumers to generate novelty as well as efficiency. Thus, in order to understand how innovative consumption of blogs occurs, we should expand our notion of a good. A good may not be adequately defined by some single function. Rather, goods appear to be multimodal in terms of functions, properties, and characteristics whose system of interactions along with their social dimensions widens the boundaries of the single good.

Finally, combined with the versatility and selfrejuvenation, the blogger's novelty-seeking, innovative consumption of blogs suggests that blogs will continue to grow in popularity in the future, and that they could dominate the genre ecology of the Internet. We believe that blogs will change the way we think about the Web and about the communication. This analysis thus illustrates how taste for novelty and novel tastes can have substantial consequences for consumer choice.

\section{REFERENCES}

1. Baker, S. \& Green, H. (2005). Blogs will change your business, BusinessWeek, (May 2). Available online at http://www.businessweek.com/ magazine/content/05_18/b3931001_mz001.htm.

2. Berlyne, D. E. (1960). Conflict, Arousal, and Curiosity. New York: McGraw Hill.

3. Blood, R. (2004). How blogging software reshapes the online community, CACM, 47(12), 53-55.

4. Blood, R. (2002). The Weblog Handbook: Practical Advice on Creating and Maintaining Your Blog. Cambridge, MA: Perseus Publishing.

5. Boissevain, J. (1979). Network analysis: A reappraisal, Current Anthropology, 20(2), 392394.

6. Bonnie, A. N., Diane, J. S., Michelle, G., \& Luke, S. (2004). Why we blog, CACM, 47(12), 41-46.

7. Earl, P. (1986). Lifestyle Economics. Consumer Behavior in a Turbulent World. New York: St. Martin's Press.

8. Edward, J. L. \& Yoon, J. (1998). Network structure and emotion in exchange relations, American Sociological Review, 63(6), 871-894.

9. Efimova, L. (2003). Blogs: The stickiness factor, Presented at BlogTalk: A European Conference on Weblogs. 
10. Herring, S., Scheidt, L., Bonus, S., \& Wright, E. (2004). Bridging the gap: A genre analysis of Weblogs, Proceedings of the $37^{\text {th }}$ HICSS.

11. Hirschman, E. C. (1980). Innovativeness, Novelty Seeking, and Consumer Creativity, Journal of Consumer Research, 7(3), 283-295.

12. Kelly, G. A. (1955). A Theory of Personality: Psychology of Personal Constructs. New York: Norton.

13. Kirzner, I. M. (1989). Discovery, Capitalism, and Distributive Justice. Oxford: Basil Blackwell.

14. Krishnamurthy, S. (2002). The Multidimensionality of Blog Conversations: The Virtual Enactment of September 11. In Maastricht, The Netherlands: Internet Research 3.0.

15. Lancaster, K. (1991). Modern Consumer Theory. Aldershot: Edward Elgar.

16. Lancaster, K. (1971). Consumer Demand. A New Approach. NY: Columbia University Press.

17. Lasica, J. D. (2001). Blogging as a form of journalism, USC Annenberg Online Journalism Review (http://www.ojr. org/ojr/workplace/1017958873.hp).

18. Lemire, B. (1991). Fashion's Favourite: The Cotton Trade and the Consumer n Britain, 16601800. Oxford: Oxford University Press.

19. Hurst, M. (2004). E-mail and ease of use: A preferred method of mass communication with Internet users, Interactions, 11(2), 55-56.

20. Mukerji, C. \& Schudson, M. (eds) (1991). Rethinking Popular Culture: Contemporary
Perspectives in Cultural Studies. Berkeley: University of California Press.

21. Scitovsky, T. (1992). The Joyless Econmy. The Psychology of Human Satisfaction. Oxford: Oxford University Press.

22. Searls, D. \& Sifry, D. (2003). Building with blogs, Linux Journal, 107, 4.

23. Shroeder, R. (2003). One path to the blog: An odyssey in tracking and sharing technology with the online higher education community, eLearn Megazine, 2003(6), 3.

24. Steele, L. (2005). Hot off the web: gossip and design guidance, The New York Times, January 27.

25. Stiglitz, J. E. \& Atkinson, A. B. (1969). A new view of technological change, Economic Journal, 79(315), 573-578.

26. Suler, J. (2000). Bringing online and offline living together: The integration principle. http://www.rider.edu/ suler/ psycyber/integrate.html.

27. Wellman, B. (2002). Designing the Internet for a networked society, CACM, 45(5), 91-96.

28. Winer, D. (2002). The history of weblogs,http://newhome.weblogs.com/historyOf Weblogs.

29. Yates, J. \& Orlikowski, W.J. (1991). Genres of organizational communication: An approach to studying communication and media. MIT: Sloan School of Management. 